\title{
Contrast enhanced CMR in acute myocarditis: what is the optimal moment for imaging?
}

\author{
Alexis Jacquier ${ }^{1 *}$, Nicolas Amabile ${ }^{2}$, Jean Yves Gaubert ${ }^{1}$, Francesca Carta ${ }^{1}$, Antonin Flavian ${ }^{1}$, Boris Maurel $^{1}$, \\ Guy Moulin ${ }^{3}$
}

From 2011 SCMR/Euro CMR Joint Scientific Sessions

Nice, France. 3-6 February 2011

\section{Introduction}

The pathological processes (ie alteration of myocardial perfusion) that occur during the acute phase of a myocarditis, are different from those of myocardial infarction. Myocardial enhancement kinetics might be different in acute myocarditis compared to myocardial infarct that may impact the optimal moment for imaging acute myocarditis.

\section{Purpose}

To compare the kinetics of gadolinium in acute myocarditis and acute myocardial infarction and 2) to establish the best interval between contrast injection and delayed contrast enhanced (DCE) image acquisition for the diagnosis of acute myocarditis.

\section{Methods}

Ninety-nine patients were prospectively included, 17 patients with acute myocarditis and 12 with acute myocardial infarction. All patient underwent a 1.5T CMR examination. Look-Locker sequences were acquired before and after administration of $0,2 \mathrm{~mol} / \mathrm{kg}$ Gd-DOTA repeatedly during $14 \mathrm{~min}$ with the following parameters: $\mathrm{TR} / \mathrm{TE}=26.7 / 1.27 \mathrm{~ms}$, slice thickness $=8 \mathrm{~mm}, \alpha=30^{\circ}$, matrix $=192 \times 96,26$ cardiac triggered images were acquired following each non-selective inversion pulse with $\mathrm{TI}_{0}=95 \mathrm{~ms}, \Delta \mathrm{TI}=25 \mathrm{~ms}$. The apparent longitudinal relaxation rate (R'1) from left ventricular blood, enhanced and normal myocardium and were calculated. Delayed contrast enhanced (DCE) images were acquired at 5,10 and $15 \mathrm{~min}$ after contrast injection $(\mathrm{TR} / \mathrm{TE}=650 /$ $1.56 \mathrm{~ms}$, slice thickness $=7 \mathrm{~mm}$, spacing $=0, \alpha=10^{\circ}$, and matrix $=152 \times 134$. The inversion time $=270-325 \mathrm{~ms}$. Signal

\footnotetext{
${ }^{1} \mathrm{CHU}$ La Timone, CEMEREM, Marseille, France

Full list of author information is available at the end of the article
}

noise ratio (SNR) and contrast noise ratio (CNR) were measured and a qualitative image analysis was performed on a four points scale.

\section{Results}

A faster decline in R'1 value was measured within the area of myocardial enhancement in myocarditis compared with myocardial infarction. Myocarditis patients showed a significant decrease in CNR (from $92 \pm 58$ at $5 \mathrm{~min}$ vs $64 \pm 47$ at $15 \mathrm{~min} ; \mathrm{P}<0.0001$ ) as a function of time (Figure 1). Whereas in myocardial infarction, there was no significant difference between time points for CNR ( $92 \pm 57$ at $5 \mathrm{~min}$ vs $100 \pm 50$ at $15 \mathrm{~min} ; \mathrm{P}=\mathrm{ns}$ ). Image quality in myocarditis was significantly better at $5 \mathrm{~min}(3.6 \pm 0.6)$ and decreased over time at $10(2.7 \pm 0.5)$ and $15 \mathrm{~min}$ $(2.1 \pm 0.7 ; \mathrm{P}=0.01)$ after contrast injection (figure 1$)$.

\section{Conclusions}

The gadolinium kinetics of acute myocarditis are different from those of acute myocardial infarction. In

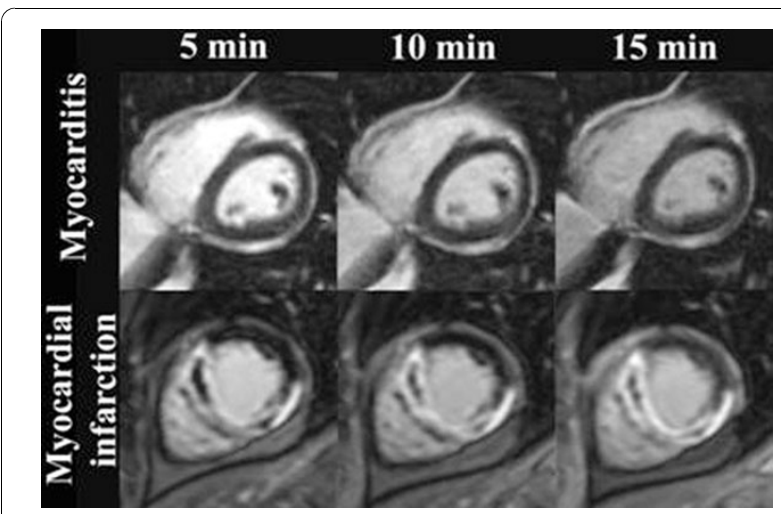

Figure 1 DCE images 5, 10 and $15 \mathrm{~min}$ in one patient with myocarditis (upper row) and in one other patient with myocardial infarction (lower row). 
myocarditis, DCE images acquired $5 \mathrm{~min}$ after contrast injection provide higher SNR, CNR and image quality compared with images collected at later times.

\section{Author details}

${ }^{1} \mathrm{CHU}$ La Timone, CEMEREM, Marseille, France. ${ }^{2}$ Marielanelongue, Paris,

France. ${ }^{3} \mathrm{CHU}$ La Timone, Marseille, France.

Published: 2 February 2011

doi:10.1186/1532-429X-13-S1-036

Cite this article as: Jacquier et al:: Contrast enhanced CMR in acute myocarditis: what is the optimal moment for imaging?. Journal of

Cardiovascular Magnetic Resonance 2011 13(Suppl 1):O36.

Submit your next manuscript to BioMed Central and take full advantage of:

- Convenient online submission

- Thorough peer review

- No space constraints or color figure charges

- Immediate publication on acceptance

- Inclusion in PubMed, CAS, Scopus and Google Scholar

- Research which is freely available for redistribution

Submit your manuscript at www.biomedcentral.com/submit 